\title{
A cultura escolar e a produção da cultura da escola com a entrada/ permanência do "novo" na escola: um ensaio sobre os seus efeitos
}

\author{
Adriana Dickel ${ }^{*}$ \\ Flaviana Demenech $^{* *}$
}

\section{Resumo}

O processo de universalização do ensino viveu diferentes momentos, impulsionado pelos meios populares organizados e pelo contexto econômico em constante transformação. Com este trabalho, pretende-se compreender as estratégias que as escolas estão produzindo para atender a grupos que, além de ter acesso à escola, permanecem nela em razão de programas sociais de diferentes naturezas e objetivos. Esses grupos levam consigo necessidades e demandas e projetam sobre esse ambiente ações, linguagens, concepções, que aprofundam a heterogeneidade presente no cotidiano escolar e tensionam a tendência à homogeneização, peculiar a esse espaço. Inicialmente, aprofundam-se aspectos desse contexto por meio da exploração de três categorias: o "novo", tendo por referência os trabalhos de Sader (1988) e de Ezpeleta e Rockwell (1989), a cultura escolar, com base em Viñao Frago (2005) e Forquin (1993), dentre outros, e a cultura da escola, por meio dos estudos de Lahire (2005) e Mafra (2003). Na sequência, com base em um estudo de caso etnográfico realizado em duas escolas públicas do município de Passo Fundo, RS, são expostas cenas que remetem a duas estratégias - acolhimento e relação família/escola - utilizadas pelas escolas para administrar as tensões que esse cenário produz. Conclui-se que, quando novos personagens entram em cena, os tensionamentos próprios do caráter público imposto historicamente à escola se exacerbam e velhas contradições se tornam mais evidentes. As escolas fazem um grande esforço para acolher e fazer com que o "novo" permaneça na escola, por vezes, reforçando o ideal de padronização e a imposição de regras próprias da cultura escolar, e, por outras, recrudescendo os problemas vividos pelas crianças e jovens, ao buscar na família apoio para pressioná-los a adequarem-se ao seu modo de operar. Observa-se, ainda, que o projeto de formação da escola sucumbe à necessidade de administrar o caos que se entranhou em seu cotidiano, sem que consiga oferecer razões aos jovens e às crianças para que assumam um lugar nesse projeto.

Palavras-chave: Cotidiano escolar. Cultura escolar. Escola. Gestão.

Recebido: 03/02/2016 - Aprovado: 17/04/2016

http://dx.doi.org/10.5335/rep.v23i1.6337

\footnotetext{
Professora do Programa de Pós-Graduação em Educação e do curso de Pedagogia da Universidade de Passo Fundo. Pós-doutora (como bolsista Capes) pela Universidad Autónoma de Barcelona, doutora e mestra em Educação pela Universidade Estadual de Campinas. É especialista em Epistemologia das Ciências Sociais e graduada em Letras pela Universidade de Passo Fundo. E-mail: dickel@upf.br

** Doutoranda em Educação pela Universidade Federal de Pelotas. Mestre em Educação pela Universidade de Passo Fundo (como bolsista Capes). Graduada em Pedagogia pela Universidade Estadual do Oeste do Paraná, Campus Foz do Iguaçu. E-mail: flavianademenech@gmail.com
} 


\section{Situando a problemática}

No Brasil, o processo de universalização do ensino ocorreu movido pelas demandas econômicas e sociais, em especial pela pressão dos meios populares organizados. Sinais de avanços da instrução pública foram notados na expansão do número de escolas, espaços cuja origem não está marcada pela presença das massas, mas por uma estrutura idealizada para a educação de poucos. A extensão das suas funções para atender a todos os grupos sociais demandou-lhe estabelecimento de novas regras e seus efeitos tornaram evidente sua gênese.

Nesse novo contexto, mais importante do que níveis de instrução apropriados à vida em sociedade, era fomentar em todos um determinado padrão de comportamento e um modo de pensar o mundo considerado adequado e socialmente aceitável. A necessidade e as estratégias de disciplinamento tinham como pressuposto a compreensão de que o poder estava em quem ofertava a instrução: “[...] lentamente os governos conseguiam intervir inclusive nas escolas particulares, mediante legislação que buscava uniformizar o calendário escolar, o controle do tempo, o currículo, os procedimentos, criando os 'sistemas educacionais nacionais"' (ARANHA, 2006, p. 201). A escola tornava-se um instrumento idôneo para o controle, com intuito de dominar e dar forma aos comportamentos da população, principalmente a subalterna. Essas atribuições e, principalmente, o poder imputado à escola, como a seleção dos conteúdos a serem ensinados, sua pertinência, sua consistência, sua utilidade, seu interesse, seu valor educativo ou cultural, esse modo de organização, resultou em uma cultura própria - a cultura escolar - e com ela a justificação de sua própria função (FORQUIN, 1993, p. 9).

Segundo Rockwell (1997), a escola teria semelhança com o trabalho de operários e empregados, já que os níveis sucessivos do sistema de ensino baseiam-se em relações hierárquicas, que distinguem os que sabem dos que não sabem: o conhecimento aparece como estranho ao conhecimento cotidiano tanto de professores quanto de alunos. Alguns aspectos da formação implícita oferecida pela escola - a formalização, a importância de cumprir as tarefas, a falta de coordenação entre as tarefas e a necessidade de trabalhar sem entender o significado geral do processo instalado - remontam ao processo de trabalho na estrutura capitalista. Portanto, a escola, com seu currículo, seus tempos, sua disciplina, institui-se e constitui-se através e por meio dessas relações de poder.

Apesar da necessidade de ofertar a todos a educação escolar, estudiosos (PATTO, 1985, 1990; SOARES, 1993) desse processo apontam para o surgimento de uma instrução diferenciada entre a elite e os meios populares. Caberia, sim, educar os meios populares, mas não demasiadamente: 
[...] com o avanço do processo de industrialização, a escola passa a ser o lugar privilegiado de formação do novo trabalhador. Começam a distinção do povo para o trabalho e a educação daqueles que conceberiam e dirigiriam o processo de produção do controle social e político, compondo sistemas duais de ensino (DICKEL, 1998, p. 36).

De todo modo, com esse movimento, os meios populares, até então desprovidos de instrução formal, foram sendo paulatinamente incorporados à escola. Esse processo que se adensa fortemente no século XIX, na Europa, produzirá forte repercussão no Brasil somente no século XX. Antes de 1960, poucas crianças tinham assento nos bancos escolares. Devido ao processo e ao avanço da industrialização e, principalmente, à quebra do silêncio da classe operária em suas lutas por tornar visíveis e garantidos os seus direitos, o processo de escolarização é profundamente alterado. Materializam discursos pela universalização da escola documentos produzidos em mobilizações capitaneadas pela UNESCO, pelo Bird, BID e OCDE (Declaração de Jomtien e de Salamanca, a Conferência de Dakar, entre outros acordos), além da Lei de Diretrizes e Bases da Educação Nacional (Lei nº 9.394/1996) e regulamentações e mudanças posteriores. Uma escola pensada para o homogêneo, uma estrutura idealizada para a educação de poucos, necessita, então, adaptar-se para receber novos sujeitos. Com o acesso paulatino dos meios populares à escola, surgem alguns problemas e conflitos que antes a escola não enfrentava. Um deles, o fracasso escolar.

Para Soares (1993), o fracasso escolar é um fenômeno complexo, caracterizado fundamentalmente pela não adesão de um sujeito ao que é proposto pela escola, o que se materializa na repetência e/ou evasão escolar. Razões para o fracasso escolar foram explicitadas por várias teorias. Muitas delas tendiam a culpabilizar a criança oriunda dos meios populares e suas relações culturais e sociais por não conseguir aprender. Resultam desse cenário teórico questões fulcrais: existe fracasso escolar ou há crianças em situação de fracasso? Se forem as crianças a causa do fracasso escolar, por que somente as crianças dos meios populares fracassam?

Os estudos sobre o fracasso escolar evidenciaram, ainda, que o acesso de crianças e jovens de meios populares à escola não é garantia de uma educação escolar que oportunize níveis de instrução adequados às demandas sociais e econômicas postas aos diferentes grupos sociais. O século XXI assistiu, no Brasil, ao avanço de medidas que visam à permanência, à não reprovação e evasão escolar, entre eles programas sociais tais como o Bolsa Família, em 2003, e o Mais Educação, em 2007. ${ }^{1}$ A pressão pela presença na escola de grupos que até pouco tempo, por mais que acessassem os bancos escolares, neles não permaneciam, tensionados, entre outros elementos, pela lógica interna da instituição, modifica essa lógica de alguma forma? De que organização, estratégias e práticas se servem a escola para gerir esse novo contexto? 
A abordagem que orienta esta exposição pauta-se na necessidade de compreender as estratégias que as escolas estão produzindo para atender a grupos que até pouco tempo, mesmo tendo acesso, não permaneciam nos bancos escolares e que, dadas as suas necessidades e demandas, projetam sobre o seu ambiente ações, linguagens, concepções, aprofundando a heterogeneidade presente no cotidiano escolar e tensionando a tendência à homogeneização tão peculiar a esse espaço. Para tanto, inicialmente, problematizar-se-á alguns elementos do contexto em que se encontra atualmente a escola, por meio da exploração de três categorias: o "novo", a cultura escolar e a cultura da escola. Na sequência, com base em um estudo de caso etnográfico, serão reconstruídas duas estratégias utilizadas pelas escolas que constituem o universo de pesquisa, a fim de problematizar as tensões que esse cenário produz dentro desses espaços e entre alguns de seus sujeitos.

\section{Quando novos personagens entram em cena na escola...}

O termo "novo", neste estudo, não é um adjetivo, mas um substantivo: designa um sujeito social historicamente constituído e originário de mudanças nos cenários econômicos e sociais, na composição de forças que atravessam as relações sociais em determinados momentos históricos. Essa designação resulta de analogia do uso feito por Sader (1988), na obra Quando novos personagens entraram em cena: experiências, falas e lutas dos trabalhadores da Grande São Paulo, 1970-1980. Nela, o autor recupera a trajetória dos movimentos sociais populares entre 1970 e 1980 e chama a atenção para o que considera a "nova configuração social" assumida pelos trabalhadores da Grande São Paulo. Segundo Chauí (1988, p. 10-12), na apresentação que faz à obra, Sader defende a presença de um novo sujeito social e histórico que assim se constitui, primeiramente, porque "sua prática os põe como sujeitos sem que teorias prévias os houvessem constituído ou designado" e, em segundo lugar, porque se trata de um sujeito coletivo e descentralizado, portador de valores de justiça, igualdade, direitos, e protagonista de protestos e lutas. Esses "novos sujeitos", as classes trabalhadoras, foram tomando espaço na sociedade, delimitando e pressionando por direitos e criando novos espaços políticos e novas relações com o espaço público. À medida que "entram em cena", colocam-se em um lugar de destaque na sociedade, fazem-se presentes e rejeitam a condição de invisibilidade:

[...] eles foram vistos, então, pelas suas linguagens, pelos lugares de onde se manifestavam, pelos valores que professavam, como indicadores da emergência de novas identidades coletivas. Tratava-se de uma novidade no real e nas categorias de representação do real [...] (SADER, 1988, p. 27). 
Esses novos sujeitos conquistam vários espaços, e um deles é a instituição escolar. A escola é requisitada, no confronto entre forças sociais e políticas, a acolher esses novos sujeitos que entram em cena. A mesma escola que, por muito tempo, abrigara uma minoria, que concebera práticas dirigidas aos grupos sociais favorecidos economicamente, que visara atender somente indivíduos dotados de linguagem, valores e costumes análogos aos seus, assiste à emergência de profundos conflitos: o velho e o novo antagonizam.

Ao se constituir historicamente como espaço de poucos, produziu-se o que no campo da pesquisa educacional designa-se como cultura escolar. Trata-se de uma série de normas, ritos, ritmos, hierarquias, critérios de ordenamento e classificação, linguagem, entre outros elementos, que se constituiu como objeto de transmissão deliberada no contexto das escolas e tendencialmente refratária a transformações sociais e culturais, às gerações que lhe acedem e às políticas que visam interferir em sua lógica (VIÑAO FRAGO, 2005). Para Abramowicz, "A escola atual procura homogeneizar tudo e repelir o que for diferente, o heterogêneo, pela evasão, pela repetência e também pela classe especial - que é a classe homogênea dos diferentes" (1995, p. 65).

Isso não significa dizer que a escola é a mesma para todos. Essa cultura é vivida de modo peculiar pelas pessoas, produzindo o que Ezpeleta e Rockwell (1989) designam como "história não documentada". São elas que reconstroem e respondem a tensões e contradições e que organizam a sua vida nesse espaço, suas ações e concepções, produzindo a cultura da escola. Nesse sentido, a presença do heterogêneo é inevitável.

Essa presença, em um ambiente constituído para o homogêneo, produz relações não necessariamente previstas e aciona disposições até então ausentes no ambiente escolar. Essas disposições, segundo Lahire (2005), são produzidas pelo indivíduo no curso das interações com os outros. Por meio delas, ele constrói, estabelece, solidifica formas de pensar, agir, sentir, condicionadas pelo processo de socialização em que foram produzidas.

Os pesquisadores da "cultura da escola" buscam o ethos cultural da escola, a sua marca ou identidade cultural. A discussão está voltada aos "processos mais particulares e contingentes da escola, privilegiando as análises culturais do cotidiano" : os acontecimentos, as interações sociais e culturais, as relações de poder, os saberes (re)produzidos. O objetivo principal é desvendar o desconhecido da cultura e da vida dessa instituição de ensino por meio do instituído, do vivido e do construído (MAFRA, 2003, p. 126-128). Para Forquin, a cultura da escola revela-se em "características de vida próprias, seus ritmos e seus ritos, sua linguagem, seu imaginário, seus modos próprios de regulação e de transgressão, seu regime próprio de produção e de gestão de símbolos" (1993, p. 167). 
Se até o final do século passado, somente permaneciam na escola aqueles que se submetiam à sua lógica e que se conformavam à cultura escolar, desde a última década daquele século, impõem-se à escola políticas e movimentos de efetiva universalização da educação formal, vinculados a programas de permanência das crianças de todos os grupos sociais na escola.

$\mathrm{Na}$ medida em que crianças com deficiência, crianças de meios populares, adultos afastados da escola pela busca do trabalho em idade prematura, famílias sem tradição escolar, indígenas, caboclos, quilombolas, filhos de pequenos agricultores, de sem-terra, de trabalhadores urbanos ou desempregados crônicos passam a frequentar o espaço escolar, a tornar visível à escola práticas, condutas, valores distintos dos apregoados por ela, em que profissionais de outras áreas recorrem a esse lugar como um dos remanescentes da presença do Estado junto a essa população (BOURDIEU, 1998), em que projetos/programas/políticas sociais e educacionais demandam sujeitos, práticas e organização distintas daquelas até então estabelecidas pelos profissionais da escola, configura-se no interior dessa instituição uma heterogeneidade sem precedentes em sua história.

Sader (1988) fornece evidências de que a classe operária no processo de revolução não era uma novidade, mas "um novo latente". Era algo produzido pela própria dinâmica capitalista, que foi, com o processo evolutivo, nesse percurso, avolumando-se, adensando-se, tomando forma, e que, aparentemente de modo inusitado, mostrou a sua cara a ponto de não mais se poder deixar de vê-la ou negá-la.

O "novo" neste estudo tem essa perspectiva histórica, resulta do movimento social, constituiu-se no embate das práticas sociais. Não é algo inesperado. Portanto, o "novo" de que se trata aqui não possui a conotação de novidade. É aquilo que as próprias relações sociais foram produzindo e para o que a estrutura que está dada não tem, muitas vezes, resposta. Ou, quando há tentativas de resposta, são ensaios e erros (políticas, projetos, programas) mediados por opções políticas, tendências ideológicas, pontos de vista voluntaristas, que entram na escola e logo revelam a superficialidade do seu conhecimento sobre essa instituição e esse novo que ali está. Já os profissionais que atuam na escola, à frente dos processos educativos, precisam administrar a situação gerada por esse contexto.

O "novo" a que se faz referência também está aí: nas estratégias (compreensões, práticas, projetos, discursos) produzidas por esses sujeitos para manter a escola em funcionamento e produzindo sentido na vida das crianças, dos jovens e de suas famílias e dos vários profissionais que a realizam em suas funções. Como a escola organiza-se em face desse novo sujeito social, histórico e heterogêneo? Quais as estratégias criadas pela escola para manter-se e justificar a sua função nesse novo cenário? Esse é o tema do próximo tópico. 


\section{A gestão do novo pela escola: as tensões e os seus efeitos}

Com vistas a abordar os tensionamentos e as estratégias que resultam da presença do novo na escola, foi desenvolvida uma investigação de abordagem qualitativa, do tipo estudo de caso etnográfico. Três métodos para a produção dos dados foram utilizados: a observação, registrada em diário de campo (DC), entrevistas com equipe diretiva (Ent) e análise de documentos escolares (projeto político-pedagógico, regimento escolar, regulamentação do auxílio Bolsa Família, estatísticas sobre evasão, repetência, aprovação e distorção idade/série, entre outros). Isso favoreceu o processo de triangulação, utilizado nas pesquisas qualitativas para elevar ao máximo a confiabilidade nos dados produzidos (FLICK, 2009).

O trabalho de campo foi realizado em duas escolas de periferia do município de Passo Fundo, Rio Grande do Sul (doravante denominadas Escola E e Escola I), selecionadas conforme os seguintes critérios: são instituições com corpo discente numeroso; atendem a famílias economicamente desfavorecidas; recebem crianças que cumprem medidas socioeducativas ou são beneficiadas por programas sociais e crianças com algum tipo de deficiência; oferecem programas de ampliação do tempo na escola (Mais Educação, Educação Integral). Em relação ao Índice de Desenvolvimento da Educação Básica (Ideb), outro fator observado na seleção das instituições, a Escola $\mathrm{E}$ está apresentando crescimento quanto ao índice na última década (em 2013, registrou-se a nota 5,0 para $4^{a}$ série $/ 5^{\circ}$ ano); a Escola I apresenta uma oscilação nos índices, tendo, em 2013, a nota 4,4, a maior nota já recebida pela escola para o nível $4^{\underline{a}}$ série $/ 5^{\circ}$ ano, e para o nível de $8^{\underline{a}}$ série $/ 9^{\circ}$ ano, sua última avaliação foi de 2,8 .

Ambas situam-se em bairros periféricos, a Escola E atendia a 900 crianças, em 2013, e a Escola I, a 1.108 alunos. A observação in loco, ocorrida durante os meses de novembro e dezembro de 2013, foi limitada ao espaço exterior à sala de aula. Os momentos privilegiados no processo de observação foram: a) chegada dos alunos na escola; b) atividades dos alunos no recreio; c) desenvolvimento de projetos pedagógicos (Mais Educação, Tempo Integral, Projeto da Biblioteca, Programa Nacional de Tecnologia Educacional, Sala de Recursos e outros projetos internos das escolas); d) encontro entre os docentes na sala de professores, na secretaria da escola, em reuniões pedagógicas e conselhos de classe.

A leitura exaustiva do material permitiu o reconhecimento de aspectos singulares a cada escola e de aspectos recorrentes. Nesta exposição, ${ }^{2}$ são recompostas duas estratégias, comuns a ambas as escolas, que resultaram do processo de análise de dados. Uma delas - acolhimento - remonta a fatores intraescolares, criados ou mantidos no interior da escola para gerir o novo dentro das escolas estudadas. 
Com a outra - relação família/escola -, são acionados fatores extraescolares, para gerir condicionamentos que têm origem fora da escola e que afetam a gestão da heterogeneidade constitutiva de seu cotidiano.

\section{Acolhimento}

Em um cenário em que políticas educacionais estabelecem a obrigatoriedade de frequência dos alunos na escola, essa presença precisa ser gerida pelo recurso a diferentes estratégias. Por acolhimento compreendem-se as práticas que se voltam para a criança, o jovem, a família de modo a criar um vínculo de compromisso mútuo com vistas à permanência da criança na escola.

A entrada dos alunos é um indicador da materialidade dessa estratégia. $\mathrm{Na}$ Escola E, há uma rotina. Toda manhã e toda tarde, após o sinal, os professores e a equipe diretiva da escola recepcionam os alunos no saguão principal, observam e acompanham a entrada deles na escola. Somente, então, os professores dirigem-se às salas de aula. "Enquanto os alunos entram, são recebidos com: Bom dia! Tudo bem? Como você está? Aí que bom que você veio!, principalmente proferidas pela professora Renata. Alguns alunos se dirigem até ela, a abraçam, lhe cumprimentam, os pais dos alunos também" (DC). Após a entrada dos alunos, a coordenação percorre o pátio e os corredores, chamando e colocando em sala de aula os alunos que ainda permanecem fora dela, observando também se os professores já estão em sala e se há algum problema urgente a ser resolvido.

Conforme a equipe diretiva da Escola E, o seu objetivo é receber os alunos bem, para que eles sintam-se parte da escola. Suas integrantes declaram que receber bem o aluno é o mais importante, como também conhecer a sua realidade, conhecer o que se passa com ele, para assim saber como melhor trabalhar com ele: “[...] se me perguntar de um aluno, a não ser que seja novo, eu sei o nome, o endereço, sei de quem é filho, mora aonde, qual é a situação, aprendemos a conviver [...]" (Ent). Uma das estratégias observadas é a de receber bem esse aluno, encaminhá-lo para a sala de aula, fazer com que ele entre e se acomode: "[...] Faço com que eles entrem, porque a dificuldade é eles entrarem e ficarem em sala de aula, e que aquele dia renda, essa é a minha preocupação. Que os professores estejam em sala de aula e consigam desenvolver o trabalho que propõem para aquele dia [...]" (Ent).

Na Escola I, o portão principal, que dá acesso ao interior da escola, permanece sempre aberto. Não há porteiro ou responsável cuidando do portão; os alunos e as pessoas da comunidade, ou qualquer pessoa, têm acesso livre à escola. As crianças chegam e reúnem-se em grupo para brincar, conversar, passear pelo pátio ou pela quadra de esportes. Alguns alunos são trazidos por responsáveis, que permanecem 
com eles até o momento de entrada em sala de aula ou até que o professor apareça no corredor; outros são deixados no pátio ou em frente à escola. A maioria dos alunos chega sozinha (DC).

Já o acesso ao prédio principal (que dá acesso à secretaria, às salas de professores, de recursos, de informática, de coordenação, direção, orientação e a algumas salas de aula) é permitido somente para funcionários e professores. Ao soar o sino, os alunos entram nas salas de aula, onde estão seus professores.

Tanto a Escola I quanto a Escola E têm figuras carinhosas dentro do ambiente escolar. Na escola I, destaca-se a professora Maria, que tem grande interação com alunos e funcionários. Enquanto caminha pelo pátio da escola, em alguns momentos antes de soar o toque de início da aula, a professora para e conversa com as crianças, professores e funcionários, cumprimenta, pergunta como estão, se lhes falta alguma coisa (DC).

A professora Carmem, também da Escola I, tem um vínculo estreito com os alunos. Quando encontrada pelos corredores, é saudada pelos alunos, que a abraçam; ela retribui a saudação com carinho, abraçando-lhes e oferecendo sorrisos.

Olha, uma das principais mudanças que nos propusemos a fazer, foi a forma dos alunos serem tratados. Valorizar a conversa, a fala com ele, não mais aquela questão da punição. É uma... escola, está no contexto de exercício, valores, da diferença. Estamos tentando fazer um resgate, do que falou-se, através da conversa, do diálogo, da paciência. [...] Estamos fazendo uma construção, a partir da forma como eles são vistos (Ent).

Em relação aos estudantes que faltam por um longo período, são tomadas algumas providências. Uma delas é o telefonema para a residência do aluno para verificar o porquê da sua ausência em sala de aula. Outra opção é o contato com a família para esclarecer as consequências da não presença do aluno na escola, inclusive com a perda do Bolsa Família. Se o aluno ainda continuar faltando, é tomada outra providência: encaminha-se o caso ao Conselho Tutelar. Essas são as estratégias aplicadas em busca de que os alunos não se tornem infrequentes e continuem frequentando as aulas.

Se, por um lado, existe um movimento que contribui para criar um enlace afetivo com a escola, compreendendo a sua realidade, por outro, existem elementos que expõem algumas contradições. Um deles diz respeito ao uso do tempo por parte dos alunos. Durante o período de campo, foram reincidentes momentos em que alunos eram vistos caminhando pelo pátio, principalmente no primeiro e no último horário de aula. Observada a situação, dois ou três professores reúnem-se para buscá-los e reencaminhá-los à aula. Alguns deles escondem-se atrás das árvores para conversar, outros são levados às salas, enquanto que aos alunos do turno inverso é solicitado que se retirem do pátio da escola. 
Observou-se, ainda, o envolvimento das crianças com tarefas que não correspondem a uma intencionalidade pedagógica e a dispensa dos alunos antes do horário previsto em virtude da ausência de professor. Essas duas práticas ocorrem tanto na Escola E como na Escola I. Por vezes, as crianças permanecem sem uma atividade direcionada, ocupadas com algo que não necessariamente está previsto no planejamento da professora, com a justificativa de manter o aluno na escola, mesmo que com uma atividade informal ou sem qualquer atividade, a fim de não dispensá-lo antes do horário previsto.

Essa redução no tempo de aula, seja por falta de professores - "Duas turmas foram liberadas, por não haver professores, devido ao passeio das $8^{\mathrm{a}}$ séries" (DC) -, seja em virtude do horário de ônibus dos professores - "A aula terminou mais cedo, não foi alegado o porquê do término. O horário para terminar as aulas no período vespertino seria às $17 \mathrm{~h} 30$. A alegação pelo horário diferenciado do término da aula é o horário do ônibus dos professores" (DC) -, esse fato foi observado em ambas as escolas.

A professora Renata comenta, em uma conversa informal, que a política da escola quanto aos atrasos dos alunos tem base no pensamento de que "antes tarde do que nunca". Essa política faz parte do cotidiano da escola, visto que, no período matutino, os alunos já são maiores, alguns não querem mais vir à aula, ou por desinteresse ou por necessidade de trabalho, já que as condições financeiras da comunidade são desfavoráveis. Segundo a professora, "é um avanço quando eles vêm; por isso, não se dá importância ao atraso, o importante é eles estarem presentes" (DC). Ela argumenta que os professores não gostam dessa estratégia; eles reclamam que o atraso dos alunos prejudica o andamento da aula. A professora diz saber disso, mas, para ela, é melhor deixar o aluno ficar e ele estar na escola do que fora dela. Ela não concorda em fazer o aluno perder a manhã toda em virtude de quinze minutos de atraso.

Esse fato se mostra perceptível no dia a dia da escola. Cerca de 8 horas da manhã, os alunos ainda estão chegando; muitas vezes, a diretora adverte-lhes do atraso verbalmente, mas nunca em um documento oficial ou de modo a impedir a entrada. A advertência, inclusive, é de forma alegre e carinhosa:

Meu Deus! Já é quase hora do almoço, e você está vindo agora? Nossa, o que é isso? Achei que tinha que te buscar em casa! Não precisa correr, pode andar com calma, você não está atrasado! Meninas, vocês ficam se maquiando muito para virem lindas à escola e acabam se atrasando! (DC).

Em todas as falas, a professora Renata faz com que os alunos sorriam ou respondam-lhe com um bom dia ou de forma carinhosa.

Essa estratégia remete a um modo de viver a escola em sua singularidade, constituindo-se como um dado da cultura de cada uma dessas escolas. No entanto, 
a permanência das crianças é regulada pela cultura escolar, pelas práticas de controle do espaço, pela disposição do tempo pré-estabelecido, pela permanência sem que necessariamente o trabalho a ser desenvolvido impacte sobre sua formação ou sobre o sentido da escola para elas.

A cena relatada a seguir registra uma conversa com um aluno dos anos iniciais da Escola E, que apresenta alguns pontos marcantes sobre a difusão dessa cultura no ambiente escolar.

A professora do aluno L. chama a professora Neiva pedindo que ela converse com o aluno, pois o mesmo, dito com as palavras da professora, só incomodava, não copiava, e estava sempre sem material e ainda queria mandar na professora, falando para a mesma: pega isso para mim, faz isso para mim. A coordenadora o leva para uma sala reservada para terem uma conversa.

Professora Neiva: L. você tem que dobrar a língua para falar com o professor. Tua obrigação é vir para a escola com a cabeça para trabalhar, e trazer lápis, borracha e caderno. Faz analogia com o soldado que vai à guerra sem armas. Aqui na escola é a mesma coisa, sem material escolar não adianta para nada, não aprende. A escola ganha alguns materiais e dão para vocês, mas não é sempre que isso acontece, é um tanto de material e acabou. Você chama a professora de você, mandando ela pegar as coisas e fazer as coisas para você. O professor é superior a você, você tem que respeitá-lo. Nós percebemos aqui na escola que quando na casa do aluno não tem respeito, ele traz um desrespeito junto com ele para a escola. [...] O mundo tem regras, e aqui na escola também. Você está fora da faixa etária de idade, você tem que se adequar a sua turma, a seus colegas. Você está na escola tem que respeitar colegas e professores, e ponto final. Agora me diga, por que você está agindo desta forma?

Aluno L.: Porque hoje não é meu dia.

A professora Neiva explica que as pessoas não podem agir desta forma; quando se tem um problema fora da escola, deve-se deixar ele lá fora. Dentro da escola tem que haver respeito, adaptação às regras do mundo e da escola. E concluindo o chama de inteligente e lhe diz que sabe que ele não é dessa forma, e os dois fazem um combinado: de que o aluno deverá melhorar seu comportamento em sala de aula (DC).

Está explícito nessa cena que a instituição escolar, além de um lugar para instrução dos indivíduos, é também, como se afirmou anteriormente, um local que transmite hierarquias e valores por meio de sua própria organização. Com a presença do novo, a evocação explícita desses parâmetros torna-se mais sistemática, uma vez que tensionamentos tais como o exposto ocorrem diariamente. No trabalho de campo, observa-se um cotidiano sendo administrado em meio à emergência de acontecimentos que ocorrem na sala de aula, nos corredores e nos espaços externos. Muitas vezes, os profissionais conseguem tão somente administrar o caos, com o objetivo de amenizar as tensões instauradas no ambiente escolar. Isso também aprofunda o caráter contraditório entre o que se deseja que a escola seja e o que ela consegue necessariamente realizar. Frequentemente, busca-se fora da escola apoio para atender a essas demandas, como na família. 


\title{
Relação família/escola
}

Principalmente a partir do século XIX, a educação familiar passou a ser insuficiente para a formação das novas gerações, e espaços próprios para ensinamentos e para estudar "através de livros" foram sendo instalados (ARIÈS, 2011, p. 157). Com a assunção da educação escolar, a família passa a dividir com a escola a função de educar e, com o tempo, passa a ser vítima da desconfiança sobre sua efetiva condição de protagonizar esse processo (FARIA FILHO, 2000).

Segundo Faria Filho (2000, p. 45), a forma e a intensidade das relações entre escolas e famílias variam de acordo com tempo, espaço, classe social, ocupação dos pais, nível de escolarização. Para o autor, atualmente, observa-se uma maior necessidade de estabelecer-se um efetivo diálogo entre a escola e a família, visto que, segundo o Estatuto da Criança e do Adolescente, a educação é dever de uma e de outra, e ambas devem interagir para garantir esse direito à criança e ao adolescente.

Nas duas escolas observadas, as famílias são economicamente desfavorecidas, constituídas de trabalhadores assalariados ou informais ou, ainda, de desempregados. O nível de escolaridade dos adultos, em sua maioria, não vai além do ensino fundamental. Os problemas vividos no interior das famílias são carregados com as crianças ao dirigirem-se para a escola. Nelas, evidenciam-se problemas como gravidez precoce, drogadição, alcoolismo, abandono da criança e (re)incidência no crime. Tais situações requerem das escolas ações que incidam sobre os desdobramentos desses problemas.

Na Escola E, os profissionais que trabalham ali há mais tempo afirmam que a relação da escola com a família nos últimos anos melhorou devido à participação dos pais, que estão mais próximos e dentro da escola.

\begin{abstract}
A indisciplina era muito grande, uma indisciplina generalizada. [...] fizemos de início assim: uma chamada de pais, praticamente todos os dias os pais daqueles alunos bem difíceis vinham para a escola. $\mathrm{E}$ se não vinham para a escola, a prô Julia colocava no carro, levava até em casa e conversava com esses pais. Chamamos o Conselho Tutelar várias vezes para vir dar palestra aos pais, passar nas salas falar com os alunos. Aí, foi mudando. [...] Houve essa parte de responsabilidade, dos próprios pais e dos alunos. [...] Durante a tarde eu e a prô Julia fazemos esse trabalho. Chamar os pais para trazer o aluno de volta. [...] A questão da evasão também que era bem alta, a gente procura, vai atrás, conversa, vai nas casas (Ent).
\end{abstract}

Essa preocupação com a manutenção de um canal de diálogo com a família pode ser observada em várias situações. Em vários momentos, a escola impõe aos pais o modo como deveriam relacionar-se com os filhos sem que necessariamente as condições culturais e psicológicas sejam propícias a isso, baseando-se apenas em sua autoridade para definir o que é certo e errado, até mesmo adentrando com esse 
poder moral na constituição da família. Muitas vezes, as demandas postas às famílias extrapolam as possibilidades psicológicas de seus integrantes para gerenciar essa ordem de conflitos.

Na cena descrita a seguir, a mãe, ao ser chamada para comparecer na Escola E, responsabiliza-se pelo comportamento do filho. Observa-se, no entanto, que os recursos de que ela dispõe aprofundam os problemas certamente já enfrentados pela criança, uma vez que a pressão que exercerá sobre ela inclui a violência física. Nesse sentido, o "encontro" entre família e escola pode causar no menino um sofrimento, caso a mãe não tenha condições de lidar com o problema que lhe foi colocado. Se os recursos da "conversa" mostrarem-se insuficientes, a violência física poderá ser a opção, pois é a referência de "cuidado" que ela traz consigo.

A mãe chega na escola e se dirige à coordenação da escola $E$, pois havia sido chamada para conversar sobre as ações de seu filho. A professora Rojane expõe para a mãe que o filho dela estaria gazeando aula [...].

Mãe: Bom dia, sou mãe de um aluno, vim porque vocês me chamaram e disseram que o meu filho estava fugindo da escola. Mas em casa eu conversei com ele, e ele me disse que ontem veio na escola, e até fez uma prova.

Professora Rojane: Fui eu que Ihe chamei, mãe. E sim, ele está gazeando aula, porque eu mesma vi. No início foi difícil reconhecer, mas quando eu reconheci, pensei na hora em lhe chamar para conversarmos.

Mãe: Ah, então chama ele aqui, que eu quero tirar essa história a limpo, chama ele porque eu vou arrancar o couro dele aqui mesmo. Eu vou bater nele aqui mesmo, porque estou doente, me recuperando, e ele me apronta isso.

Professora Rojane: Não, mãe, por favor, se acalme, aqui a senhora não poderá fazer nada. Se a senhora fizer algo aqui, eu terei que denunciar e processar. Em casa a senhora vê que medidas tomar, mas aqui nós chamaremos ele apenas para conversar.

Mãe: Então chama ele porque eu quero ver se ele mente na minha cara novamente.

Professora Rojane: Já foram chamar, mãe. Pode deixar que esclareceremos essa história.

Enquanto foram chamar o aluno, a mãe falou que está muito doente e que não aceitaria ele gazear aula e ainda mentir.

O aluno chegou e a mãe já foi o questionando.

Mãe: Você estava aqui na escola fazendo a prova ontem, ou não?

Aluno: Sim, eu fiz a prova.

Professora Rojane: Isso é verdade, você fez a prova, mas o que aconteceu depois que você terminou a prova? [...]

Mãe: Então porque você mentiu para mim. Você me acha com cara de boba, eu vou te falar só uma coisa, você se comporta aqui na escola e não me gazeie mais, pois nós teremos uma conversa quando chegar em casa.

O aluno apenas abaixa a cabeça.

Mãe: Professoras, quando ele sair da escola ou não estiver se comportando, me liga que eu venho aqui. 
Professora Rojane: Pode deixar que ligamos, sim [...]. Mas pode ficar tranquila mãe que sempre ligamos quando acontece algo com os alunos.

O aluno voltou à sala novamente, e a mãe se despede da coordenação, agradecendo (DC).

A família, ao ser cobrada por seu filho não se enquadrar nos padrões exigidos pela escola, repassa essa advertência, geralmente por meio de castigos às crianças, pois a escola não pode mais fazer uso desses elementos de controle pedagógico. $\mathrm{Na}$ Escola I, fatos como o exposto também ocorrem, demonstrando o lugar da criança no caminho entre a escola e a família e o quanto a aproximação entre as duas instituições pode ser cruel para ela, inclusive pelo olhar da própria criança. A cena apresentada a seguir corrobora essa afirmação:

M. é um aluno do $5^{\circ}$ ano, da professora Rosalina. A professora lhe avisou que ele não poderia mais entrar na sala dele sem a presença dos pais. Ela veio até a orientação pedagógica e avisou que havia feito tal procedimento no dia anterior, e que o aluno veio na escola, mas não trouxe um de seus responsáveis, e assim não iria permitir o aluno permanecer na aula.

O aluno procura a professora Carmem para conversar; chorando ele explica que não poderia avisar a mãe, pois tinha medo.

Aluno M.: Prô Carmem, eu não posso falar para minha mãe vir aqui, se eu falar para ela, ela vai achar que eu aprontei e vai me bater.

Professora Carmem: E você não aprontou?

Aluno: Sim, mas é que ela vai me bater (DC).

Nas observações, destacou-se a expectativa que existe nas duas escolas em relação à família. Em alguns episódios e em falas da equipe diretiva, argumenta-se que a família deveria estabelecer limites, ensinar os princípios básicos da boa convivência com as pessoas e, ainda, hábitos de boa alimentação e higiene pessoal. Há uma cobrança, de parte da escola, sobre as funções da família na participação do aprendizado e da educação dos alunos. Essa situação ocasiona alguns conflitos dentro do ambiente escolar, como uma relação instável na interação família/escola. Outro aspecto que contribui para o aumento dos conflitos é o fato de a escola declarar que os pais não estão se responsabilizando pela educação dos filhos, deixando a responsabilidade de educar apenas à escola, não comparecendo quando chamados por causa das suas condições de trabalho, por não terem tempo ou porque não consideram necessário, como se destaca na fala da professora Neiva da Escola E:

Percebemos que... a família, devido às necessidades de trabalho, de manter a casa, eles estão deixando na verdade os alunos, os filhos por conta da escola. É isso que percebemos. Muitas vezes chamamos a família, os pais não vêm. Claro que tem outros pais que estão aí, mesmo sem combinarmos com eles, se chamar, eles vêm. E nós percebemos a diferença do aluno que tem assistência da família, que colabora, auxilia em casa, com aquele aluno que não têm essa assistência (Ent). 
A parceria entre a família e a escola enfrenta, entre outros problemas, a distinção de papéis que cada uma assume. Na cultura escolar, estão muito bem demarcados e definidos os papéis e a função tanto da escola como da família dentro do processo educativo e no ambiente escolar. Um dos marcos históricos na constituição da instituição escolar foi o reconhecimento de que o poder estava centralizado em quem ofertava a instrução. Essa autoridade pedagógica apresenta-se muito fortemente no cotidiano escolar, principalmente nos discursos em que se responsabiliza a família pelo não aprendizado do aluno ou por estar deixando a incumbência de educar os filhos apenas à escola. Segundo a professora Valéria, da Escola E, um dos problemas que ocorre, dificultando a permanência, a frequência e o atendimento da criança, é a família: "Muitas das famílias não se importam com estes alunos, entregam os alunos aqui, não os ajudam ou até mesmo não os trazem" (DC).

A mesma situação também se observa na Escola I, quando os professores reconhecem que seus alunos têm capacidade de aprender, mesmo perante a sua condição social, porém, não progridem por culpa dos pais, pelo fato de eles não ajudarem os filhos.

Os professores que estão na sala dos professores conversam sobre distintos assuntos. Um deles chama a atenção: as professoras conversam sobre os alunos e os respectivos aprendizados.

Professora: Os alunos daqui tem capacidade, não é que eles não conseguem, eles conseguem, mas não estudam, não fazem, não querem. Por isso, que não dá para puxar muito com eles, colocar o conteúdo e cobrar lá em cima, pois eles não acompanham. E a culpa disso tudo é dos pais. Cadê os pais dessas crianças? Eles não fazem nada, não ajudam os filhos. Fica tudo para a escola.

As outras professoras só balançam a cabeça positivamente (DC).

Essa perspectiva do fracasso escolar como algo que se explica pelo contexto familiar da criança permite retomar a noção de habitus: um sistema produzido no passado e orientado para uma ação no presente, o "produto da interiorização dos princípios de um arbitrário cultural capaz de perpetuar-se após a cessação da AP [ação pedagógica] e por isso de perpetuar nas práticas os princípios do arbitrário interiorizado" (BOURDIEU; PASSERON, 1975, p. 43-44). Muitas vezes, a escola demonstra acreditar que os alunos dos meios populares têm tendência a fracassar devido à situação familiar e econômica ou pela interiorização das estruturas do mundo social.

Segundo Charlot (2005), o sujeito constrói-se pela apropriação de um patrimônio humano, pela mediação do outro; porém, isso contribui para a formação dos seus desejos, não para o seu sucesso escolar ou fracasso escolar. Para esse autor (2000, p. 16-18), o fracasso escolar não existe; o que existe são alunos em situação de fracasso. O fracasso não deveria ser munido de "não ter" ou "não ser". 
O aluno que não se encaixa nos padrões expressos pela cultura escolar, que resiste às imposições da escola ou não chega aos resultados esperados, que transgride as regras, que apresenta condutas não aceitáveis perante os padrões escolares, está em situação de fracasso.

\section{Considerações finais}

A universalização da educação escolar pública trouxe para dentro das instituições um contingente multifacetado de situações que reitera a tese exposta por Ezpeleta e Rockwell (1989), segundo a qual a escola constitui um processo inacabado de construção para o qual convergem relações sociais, culturais e históricas, sujeitos com diferentes trajetórias e expectativas. Essa heterogeneidade que adentra a escola impacta sobre a cultura escolar e confronta-se com a homogeneidade impregnada em seu projeto cultural. Cada escola responde a isso produzindo modos de operar e de se organizar em face dessa complexidade.

No contexto atual, quando novos personagens entram em cena nas escolas, os tensionamentos já existentes pelo caráter público que a ela foi imposto historicamente se exacerbam, e velhas contradições tornam-se mais evidentes, assim como novas contradições são produzidas. Se há décadas o problema das camadas populares era o acesso à escola, há tempos já não o é mais. Se há poucos anos, o seu problema era a permanência, atualmente há muitas razões para nela permanecer.

Uma das conclusões a que o trabalho exposto chega é a de que as escolas fazem um grande esforço para acolher e fazer com que o "novo" permaneça na escola. Por vezes, com esse intuito, reitera-se o ideal de padronização e a imposição de regras próprias da cultura escolar, os mecanismos de homogeneização e de eliminação dos movimentos, pensamentos e ações do heterogêneo, o que causa uma diversidade de tensões e contradições no ambiente escolar. Por outras, recrudescem os problemas vividos pelas crianças e jovens ao buscar na família, por exemplo, recursos para pressioná-los a adequarem-se ao seu modo de operar. Esses conflitos são próprios de cada escola e estão ligados à história singular de cada uma. O trabalho de campo evidenciou, ainda, que, devido à emergência dos acontecimentos, muitas vezes, o projeto de formação da escola sucumbe à necessidade de administrar o caos que se estabeleceu em seu cotidiano. No impulso por dar respostas a ele, dizeres e fazeres se contradizem frequentemente.

Outro elemento importante a considerar diz respeito ao fato de que as estratégias de gestão da presença desses novos personagens minimizam os conflitos que esse quadro gera, mas pouco oferecem de razões intrínsecas à escola para que jovens e crianças tomem parte de seu projeto de formação. As culturas das escolas 
observadas denotam um esforço extenuante de parte de seus profissionais para garantir a assiduidade das crianças, mantendo-se frágeis no que se refere a situações de desenvolvimento e de aprendizagem que favoreçam a elaboração de uma justificativa para sua permanência para além de fatores extraescolares.

Caberá a outros estudos cercar as várias outras formas de enfrentamento que as escolas estão produzindo face ao contexto atual. Espera-se que, entre elas, no bojo da cultura gestada em cada uma, existam aquelas que ocupem as brechas deixadas à disposição da vontade e nelas depositem a sua capacidade de criar um lugar de produção de sujeitos, que sejam capazes de gerir a vida de posse das várias possibilidades que os conhecimentos elaborados lhes abrem. Isso permitirá voltar a pensar que é possível uma escola que se justifique para além de seu ideário homogeneizante e disciplinador.

\section{The school culture and the culture of the school with the input / stay of "new" at the school: an essay on its effects}

\section{Abstract}

The universalization process of education has gone through different periods, driven by popular environments and an ever-evolving economic context. This paper examines strategies utilized by schools to serve groups that not only have access to education, but also continue in it due to requirements from social programs and help from education policies. Those groups have needs and demands and also affect their surroundings by their actions, languages and concepts, deepening the heterogeneity present in the everyday school life, and going against the natural tendency of homogenization inherent to this environment. Initially, aspects of this context are discussed by exploring three different categories: the "new", with reference to the works of Sader (1988) and Ezpeleta and Rockwell (1989), school culture, based on Viñao Frago (2005) and Forquin (1993) among others, and culture of the school with the studies of Lahire (2005) and Mafra (2003). Thereafter, based on an ethnographic study conducted in two public schools in Passo Fundo, RS, scenes that display two strategies - user embracement and family-school relation - employed by the schools to manage the tensions arisen in this scenario are shown. It follows that, when new actors enter the stage, the conflicts due to the historically imposed public nature are exacerbated, and old contradictions become more evident. Schools go great lengths to accommodate and to help new students stay in school; sometimes reinforcing the standardization ideal and imposing characteristic rules of the school culture, and, at times, intensifying the hardships endured by children and teenagers by seeking from their families pressure towards adapting to the school's way of operating. It should also be noted that, the school's formation project falls victim to the necessity of administrating the chaos entrenched in the everyday school life and fails to entice children and teenagers into contributing to its development.

Keywords: School. School culture. Everyday school life. Management. 


\section{Notas}

1 Essas políticas e programas resultaram em avanços estatísticos significativos. Em 1959, apenas 20,2\% da população entre 7 e 14 anos de idade frequentavam a instituição escolar; já em 2012, esse número estava em $98,2 \%$, tendo apenas $1,4 \%$ de abandono escolar nos anos iniciais do ensino fundamental e $4,1 \%$ nos anos finais do ensino fundamental. MEC/INEP/DTDIE. Disponível em: <http://portal.inep.gov.br/basica-censo-escolar-sinopse-sinopse>. Acesso em: 12 jun. 2016.

2 A exposição integral da análise dos dados produzidos nesse estudo encontra-se em Demenech (2015).

\section{Referências}

ABRAMOWICZ, Anete. A menina repetente. Campinas: Papirus, 1995.

ARANHA, Maria Lúcia de Arruda. História da educação e da pedagogia: geral e Brasil. 3. ed. São Paulo: Moderna, 2006.

ARIÈS, Philippe. História social da criança e da família. 2. ed. Rio de Janeiro: LTC, 2011.

BOURDIEU, Pierre. Contrafogos: táticas para enfrentar a invasão neoliberal. Rio de Janeiro: Jorge Zahar, 1998.

BOURDIEU, Pierre; PASSERON, Jean-Claude. A reprodução: elementos para uma teoria do sistema de ensino. Rio de Janeiro: Livraria Francisco Alves, 1975.

CHARLOT, Bernard. Relação com o saber: elementos para uma teoria. Porto Alegre: Artes Médicas, 2000.

. Relação com o saber, formação de professores e globalização: questões para a educação hoje. Porto Alegre: Artmed, 2005.

CHAUÍ, Marilena. Prefácio. In: SADER, Eder. Quando alguns personagens entraram em cena: experiências, falas e lutas dos trabalhadores da Grande São Paulo, 1970-80. Rio de Janeiro: Paz e Terra, 1988. p. 9-16.

DEMENECH, Flaviana. Cultura escolar e cultura da escola: produção e reprodução. Curitiba: CRV, 2015.

DICKEL, Adriana. Que sentido há em se falar em professor-pesquisador no contexto atual? Contribuições para o debate. In: GERALDI, Corinta Maria Grisolia; FIORENTINI, Dario; PEREIRA, Elisabete Monteiro de Aguiar (Org.). Cartografias do trabalho docente: professor(a)-pesquisador(a). Campinas: Marcado de Letras do Brasil - ALB, 1998. p. 33-71.

EZPELETA, Justa; ROCKWELL, Elsie. Pesquisa participante. São Paulo: Cortez; Autores Associados, 1989.

FARIA FILHO, Luciano Mendes de. Para entender a relação escola-família: uma contribuição da história da educação. Revista São Paulo em Perspectiva, São Paulo: Fundação SEADE, v. 14, n. 2, p. 44-50, 2000.

FLICK, Üwe. Qualidade na pesquisa qualitativa. Porto Alegre: Artmed, 2009.

FORQUIN, Jean-Claude. Escola e cultura: as bases sociais e epistemológicas do conhecimento escolar. Porto Alegre: Artes Médicas, 1993. 
LAHIRE, Bernard. Patrimónios individuais de disposições: para uma sociologia à escala individual. Revista Sociologia, Problemas e Práticas, Lisboa, CIES, n. 49, p. 11-42, 2005.

MAFRA, Lilian de Alvarenga. A sociologia dos estabelecimentos escolares: passado e presente de um campo de pesquisa em reconstrução. In: ZAGO, Nadir; CARVALHO, Marília Pinto; VILELA, Rita Amélia Teixeira. Itinerários da pesquisa: perspectivas em sociologia da educação. Rio de Janeiro: DP\&A, 2003. p. 109-136.

PATTO, Maria Helena Souza. A produção do fracasso escolar: histórias de submissão e rebeldia. São Paulo: T. A. Queiroz, 1990.

O sistema escolar brasileiro: notas sobre a visão oficial. In: (Org.). Introdução

à psicologia escolar. São Paulo: T. A. Queiroz, 1985. p. 25-32.

ROCKWELL, Elsie. De huellas, bardas y veredas: una historia cotidiana en la escuela. In: ROCKWELL, Elsie et al. La escuela cotidiana. México, Distrito Federal: Fondo de Cultura Económica, 1997. p. 13-57.

SADER, Eder. Quando alguns personagens entraram em cena: experiências, falas e lutas dos trabalhadores da Grande São Paulo, 1970-80. Rio de Janeiro: Paz e Terra, 1988.

SOARES, Magda. Linguagem e escola: uma perspectiva social. 10. ed. São Paulo: Ática, 1993.

VIÑAO FRAGO, Antonio. Espaços, usos e funções: a localização e disposição física da direção escolar na escola graduada. In: BENCOSTA, Marcus L. A. (Org.). História da educação, arquitetura e espaço escolar. São Paulo: Cortez, 2005. p. 15-47. 